\title{
The Effect of Pore Volume of Hard Coals on Their Susceptibility to Spontaneous Combustion
}

\author{
Agnieszka Dudzińska \\ Mines Ventilation Department, Central Mining Institute, Plac Gwarków, 40-166 Katowice, Poland \\ Correspondence should be addressed to Agnieszka Dudzińska; adudzinska@gig.eu
}

Received 16 September 2013; Revised 18 April 2014; Accepted 19 April 2014; Published 11 May 2014

Academic Editor: Hakan Arslan

Copyright (C) 2014 Agnieszka Dudzińska. This is an open access article distributed under the Creative Commons Attribution License, which permits unrestricted use, distribution, and reproduction in any medium, provided the original work is properly cited.

In this paper the results of the experimental studies on a relationship between pore volume of hard coals and their tendency to spontaneous combustion are presented. Pore volumes were determined by the gas adsorption method and spontaneous combustion tendencies of coals were evaluated by determination of the spontaneous combustion indexes $\mathrm{Sz}^{\mathrm{a}}$ and $\mathrm{Sz}^{\mathrm{a}}$ on the basis of the current Polish standards. An increase in the spontaneous combustion susceptibility of coal occurs in the case of the rise both in micropore volumes and in macropore surfaces. Porosity of coal strongly affects the possibility of oxygen diffusion into the micropores of coal located inside its porous structure. The volume of coal micropores determined on the basis of the carbon dioxide adsorption isotherms can serve as an indicator of a susceptibility of coal to spontaneous combustion.

\section{Introduction}

Hard coal is considered to be an organic polymer with a well-developed system of pores [1]. In this system one can distinguish submicro- and micropores and mesopores, as well as macropores. In a number of published research studies it has been suggested that micro- and submicropores are located mainly in the aromatic polymer and constitute the primary absorptive part of hard coal [2]. It appears that macropores are found on the edge of the polymer where they are formed as a result of the alicyclic and aliphatic hydrocarbons combination [2]. In the diffusion processes macropores are treated as transport arteries for the molecules of gas penetrating through mesopores into the micro- and submicropore system [3].

Self-heating of coal present in the deposit or pile can occur when the adequate amount of atmospheric oxygen reaches the sorptive system of the coal structure and stays in contact with the organic components. The process of self-heating of coal is influenced by many factors, including deposit temperature, the degree of coal fragmentation, type of coal and its rank, and moisture and ash content of coal, as well as maceral composition. Lower-rank coals having on their surface the large amounts of reactive groups containing oxygen adsorb more oxygen in the process of oxidation compared with coals of higher rank characterized by more organized structure and lower porosity [4]. The structure of hard coal is one of the factors that determines a susceptibility of coal to spontaneous combustion and influences the process of the self-heating of coal. Probably, energetic centers on the coal surface and oxygen-hydrogen groups are of great importance in this process. During the process of coal oxidation in the first place the following formations are oxidized: $-\mathrm{CH}_{\mathrm{al}}$, $-\mathrm{CH}_{\mathrm{ar}},=\mathrm{CH}_{2},-\mathrm{CH}_{3}$, and then finally multicore condensed aromatic systems [3]. Oxygen consumption will also be determined by its transport to the inside of the microporous structure of coals. Hence, of particular significance will also be a system of transport pores consisting of meso- and macropores. According to some authors, it is exactly mesoand macropores that play a great role in the processes of coal oxidation [5]. Although micropores comprise over $90 \%$ of the total pore volume, not always their large volume affects an increase in the oxidation rate of coal [6]. The kinetics of the reaction of coal oxidation depends mainly on the development of the solid-phase surface, the presence of active centers on it, and the presence and size of pores enabling transport of the gas phase. The structure of coal determines its accessibility for gases, including atmospheric oxygen, and 
this is one of the conditions of spontaneous ignition. Coal oxidation takes place both on the outside surfaces of the grains and the inside of the porous structure [7].

In this study, the authors analyzed the influence of the hard coals structure on their tendency to spontaneous combustion, using the parameter measured by gas adsorption method volume of pores. Adsorption of vapours and gases conducted on hard coals is a source of much information concerning mainly surface and porosity of coals, which are used to describe their properties. Many papers have been published in the areas of gas adsorption such as carbon dioxide, methane, water, carbon monoxide, hydrogen, and hydrocarbons [8-15].

\section{Currently Used Methods for Determination of a Susceptibility of Coal to Spontaneous Combustion}

The self-heating phenomenon occurs when the heat emitted as a result of contact between hard coal and oxygen is accumulated. In consequence of this accumulation heating up of coal in the deposit takes place, and then, under favorable conditions, the temperature of coal rises and after reaching the ignition temperature an endogenous fire can occur. Endogenous fires are a real threat both to safety of mining crews and to individual processes regarding coal, as from mining, through transport, to recycling; they also cause huge financial losses. The phenomenon of self-heating of hard coals was studied repeatedly, and yet the course of this complicated process is still not entirely known. The complexity of the process of coal oxidation in the deposit results from the impact of many factors associated with this process, whose role in it is not always easy to describe or interpret. From the work safety point of view the proper evaluation of the process of self-heating of coal is extremely crucial as it enables full control over the course of this phenomenon and thus, if needed, an inhibition of its further development in order to prevent dangerous and costly fires. One of the elements of fire hazard assessment is to study the susceptibility of coals to spontaneous combustion. For many years attempts have been made to develop methods for determining the self-ignition tendencies of hard coals. A number of hypotheses and theories of this process have been put forward, including the pyrite theory, phenol theory, and coal-oxygen complex theory. There have been distinguished four groups of methods based on adiabatic calorimetry, isothermal calorimetry, sorption of oxygen, and the rate of temperature rise of a sample in relation to the temperature of a specified reference system [16].

Among many presented methods for evaluation of the spontaneous combustion tendency of coal much space has been devoted to the method of adiabatic calorimetry $[17,18]$, which involves measuring the amount of heat emitted under certain fixed external conditions and recording changes in temperature of a coal sample or in the amount of evaporating moisture. This method is useful for long-term processes associated with low-temperature oxidation of coals. In the method of oxygen sorption, in turn, the amount of oxygen used in the process of coal oxidation during a laboratory test is the parameter which determines the qualification of a given coal for a group of low, medium, or high spontaneous combustion susceptibility [19]. In other methods, the critical temperature, which is the lowest temperature at which under laboratory conditions self-heating of coal takes place, is determined and then this temperature is a criterion for the classification of coals as more or less prone to spontaneous combustion [20].

In Poland the currently used method for examination of hard coals tendencies to spontaneous combustion is the Olpinski method covered by the standard PN-93/G-04558.

\section{Experimental Part}

Laboratory tests were carried out on 18 samples of hard coals having varied degrees of metamorphism and different susceptibility to spontaneous combustion, collected from exploitable coal seams in Polish mines. From a laboratory sample of each coal, prepared in accordance with the standard PN-90/G-04502, by means of Fritsch sieves a grain class of $0,063-0,075 \mathrm{~mm}$ was isolated. Coal samples of this grain size were examined to determine the values of coal spontaneous combustion indexes and tested for adsorption.

3.1. Determination of the Spontaneous Combustion Index of Coal. Determination of the spontaneous combustion index of coal is performed on the basis of the standard PN93/G-04558 "Hard Coal Determination of the spontaneous combustion index." The principle of this method lies in the continuous measurement of the temperature of the pellet made from tested coal, introduced into the air stream at $546 \mathrm{~K}$ and $463 \mathrm{~K}$ and in the determination of the rate of temperature increase of this pellet at adiabatic points. Coal pellets are made from a specially isolated grain class of $0.063-0.075 \mathrm{~mm}$. In this method spontaneous combustion index $\mathrm{Sz}^{\mathrm{a}}[\mathrm{K} / \mathrm{min}]$ is determined-that is, the rate of temperature increase of coal after its oxidation in air at $546 \mathrm{~K}$ in an adiabatic (reaction) chamber and similarly index $\mathrm{Sz}^{\mathrm{a}^{\prime}}[\mathrm{K} / \mathrm{min}]$ at $463 \mathrm{~K}$. The activation energy is also determined-that is, the minimum energy that a group of molecules must have in order for a reaction to occur, expressed by a value of $A$ in the following Arrhenius equation:

$$
k=k_{0} e^{-A / R T},
$$

describing the relationship between a reaction rate constant $(k)$ and temperature $(T)$, where $A$ is the activation energy, $R$ is the universal gas constant $e-2,718$, and $k_{0}$ is preexponential factor.

The activation energy is expressed by the following formula:

$$
A=96,79 \log \frac{\mathrm{Sz}^{\mathrm{a}}}{\mathrm{Sz}^{\mathrm{a}^{\mathrm{a}}}}, \mathrm{kJ} / \mathrm{mol} .
$$

On the basis of the values of coal spontaneous combustion index $\mathrm{Sz}^{\mathrm{a}}$ and the activation energy a division into five groups of spontaneous combustion according to the standard PN93/G-04558 has been made. This division is shown in Table 1. 
TABLE 1: Classification of coal by a susceptibility of spontaneous combustion.

\begin{tabular}{lccl}
\hline $\begin{array}{l}\text { Spontaneous combustion index } \\
\mathrm{Sz}^{\mathrm{a}}(\mathrm{K} / \mathrm{min})\end{array}$ & $\begin{array}{c}\text { Activation energy of } \\
\text { coal oxidation } A \\
(\mathrm{~kJ} / \mathrm{mol})\end{array}$ & $\begin{array}{c}\text { Group of spontaneous } \\
\text { combustion }\end{array}$ & $\begin{array}{l}\text { Evaluation of a susceptibility of coal to spontaneous } \\
\text { combustion }\end{array}$ \\
\hline$\leq 80$ & $\begin{array}{c}76-67 \\
<46\end{array}$ & I & $\begin{array}{l}\text { Coal of a very low spontaneous combustion susceptibility } \\
\text { Coal of a low spontaneous combustion susceptibility }\end{array}$ \\
$>80$ and $\leq 100$ & $>42$ & III & $\begin{array}{l}\text { Coal of a medium spontaneous combustion } \\
\text { susceptibility }\end{array}$ \\
$>100$ and $\leq 120$ & 42 or less & IV & Coal of a high spontaneous combustion susceptibility \\
$>120$ & $\begin{array}{c}34 \text { or less } \\
\text { No standarization }\end{array}$ & V & $\begin{array}{l}\text { Coal of a very high spontaneous combustion } \\
\text { susceptibility }\end{array}$ \\
\hline
\end{tabular}

TABLE 2: The values of spontaneous combustion indexes and the activation energy for individual coal samples with the corresponding group of spontaneous combustion.

\begin{tabular}{|c|c|c|c|c|}
\hline Samples & $\begin{array}{c}\text { Spontaneous } \\
\text { combustion index } \\
\mathrm{Sz}^{\mathrm{a}}(\mathrm{K} / \mathrm{min})^{\mathrm{a}}\end{array}$ & $\begin{array}{c}\text { Spontaneous } \\
\text { combustion index } \\
\mathrm{Sz}^{\mathrm{a}^{\prime}}(\mathrm{K} / \mathrm{min})\end{array}$ & $\begin{array}{c}\text { Activation energy of } \\
\text { coal oxidation } A \\
(\mathrm{~kJ} / \mathrm{mol})\end{array}$ & $\begin{array}{l}\text { Group of spontaneous } \\
\text { combustion }\end{array}$ \\
\hline Rydułtowy s. 703/1 & 12 & 4 & 46 & II \\
\hline Marcel s. 712/1-2 & 13 & 3 & 62 & II \\
\hline Borynia s. 415 & 46 & 8 & 73 & I \\
\hline Chwałowice s. 405 & 46 & 7 & 79 & I \\
\hline Zofiówka s. 407 & 55 & 11 & 68 & I \\
\hline Marcel s. 507 & 57 & 12 & 65 & II \\
\hline Bielszowice s. $405 / 2$ & 71 & 17 & 60 & II \\
\hline Jankowice s. 405 & 84 & 32 & 40 & IV \\
\hline Śląsk s. 510 & 91 & 39 & 36 & IV \\
\hline Sośnica s. 413 & 92 & 31 & 46 & III \\
\hline Szczygłowice s. 405 & 92 & 32 & 44 & III \\
\hline Polska-Wirek s. 510 & 91 & 40 & 35 & IV \\
\hline Staszic s. 402 & 94 & 34 & 43 & III \\
\hline Wesoła s. 501B & 102 & 32 & 49 & IV \\
\hline Piast s. 209 & 103 & 46 & 34 & $\mathrm{~V}$ \\
\hline Mysłowice s. 501 & 104 & 45 & 35 & IV \\
\hline Piast s. 206 & 105 & 48 & 33 & $\mathrm{~V}$ \\
\hline Sobieski s. 209 & 150 & 63 & 36 & $\mathrm{~V}$ \\
\hline
\end{tabular}

The values of spontaneous combustion indexes and the activation energy for individual coal samples with the corresponding group of spontaneous combustion are shown in Table 2.

3.2. Adsorption Tests. To determine the pore volume of coal the adsorption tests on examined coal samples were performed, using carbon dioxide and nitrogen as adsorbates. The measurements of the adsorption isotherms of carbon dioxide were conducted at $298 \mathrm{~K}$ and of the nitrogen adsorption isotherms at $77.5 \mathrm{~K}$. The adsorption tests were performed applying the volumetric method with the use of an apparatus ASAP 2010 Accelerated Surface Area and Porosimetry Analyzer by Micromeritics in the range of pressure 0-0.1 MPa.
Prior to measurements hard coal samples crushed to a grain class of $0.063-0.075 \mathrm{~mm}$ were degassed under a high vacuum of $10^{-7} \mathrm{~Pa}$. During degassing they were flushed with helium for easier removal of gas residuals contaminating the coal surface.

The results obtained from the adsorption measurements comprising micropore volumes calculated according to the Dubinin-Radushkevich model based on the carbon dioxide adsorption isotherms and macropore surfaces area calculated according to the BET model based on the nitrogen adsorption isotherms are shown in Table 3. Those results were next used to plot values of spontaneous combustion indexes $\mathrm{Sz}^{\mathrm{a}}$ and $\mathrm{Sz}^{\mathrm{a}^{\prime}}$ both as a function of surface area of macropores and as a function of volume of micropores present in coal. 
TABLE 3: The values of micropores volume and surface area of macropores for individual coal samples.

\begin{tabular}{lcc}
\hline Samples & $\begin{array}{c}\text { Micropores } \\
\text { volume, } \mathrm{cm}^{3} / \mathrm{g}\end{array}$ & $\begin{array}{c}\text { Surface area of } \\
\text { macropores, } \mathrm{m}^{2} / \mathrm{g}\end{array}$ \\
\hline Rydułtowy s. 703/1 & 0.033 & 2.53 \\
Marcel s. 712/1-2 & 0.043 & 2.07 \\
Borynia s. 415 & 0.047 & 2.21 \\
Chwałowice s. 405 & 0.048 & 3.00 \\
Zofiówka s. 407 & 0.041 & 3.92 \\
Marcel s. 507 & 0.038 & 3.84 \\
Bielszowice s. 405/2 & 0.044 & 2.10 \\
Jankowice s. 405 & 0.056 & 2.02 \\
Śląsk s. 510 & 0.049 & 3.55 \\
Sośnica s. 413 & 0.050 & 2.91 \\
Szczygłowice s. 405 & 0.055 & 3.85 \\
Polska-Wirek s. 510 & 0.049 & 4.88 \\
Staszic s. 402 & 0.055 & 3.85 \\
Wesoła s. 501B & 0.059 & 6.03 \\
Piast s. 209 & 0.051 & 4.79 \\
Mysłowice s. 501 & 0.051 & 3.82 \\
Piast s. 206 & 0.072 & 8.99 \\
Sobieski s. 209 & 0.075 & 13.52 \\
\hline
\end{tabular}

\section{Results and Discussion}

4.1. Effect of Micropore Volume on a Susceptibility of Coals to Spontaneous Combustion. The main purpose of this part of the study is to determine the relationship between microand submicropore volumes of coal and the values of indexes characterizing susceptibility of coals to spontaneous combustion. Spontaneous combustion of coal is possible in the case of the reaction of specific groups in coal with oxygen. The number of coal active centers depends on the development of the inside micropores surface area and on the accessibility of active centers located in the reactive part of coal for oxygen. Micropore volume becomes then an important factor determining the ability of coal to absorb atmospheric oxygen. Larger micropore volumes cause greater exposition of coal to gases, and thus it is more likely that the process of spontaneous combustion will occur.

The method of gas adsorption enables determination of micropore volumes of materials tested and the gas most commonly used for determination of hard coals micropore volumes is carbon dioxide. Its low chemical reactivity, a proper size of the molecule determined by the so-called kinetic diameter (for carbon dioxide it amounts to $0.33 \mathrm{~nm}$ ) [21], and the low value of the activation energy are the factors favoring the possibility of carbon dioxide penetration into the pores, which are not available for other gases. According to $[22,23]$ carbon dioxide is the gas best adsorbed inside the microporous structure of hard coals. Not without significance is also the temperature at which the measurements of adsorption were performed $-298 \mathrm{~K}$, as it is the closest to the actual temperature at the bottom of the mine and thus provides

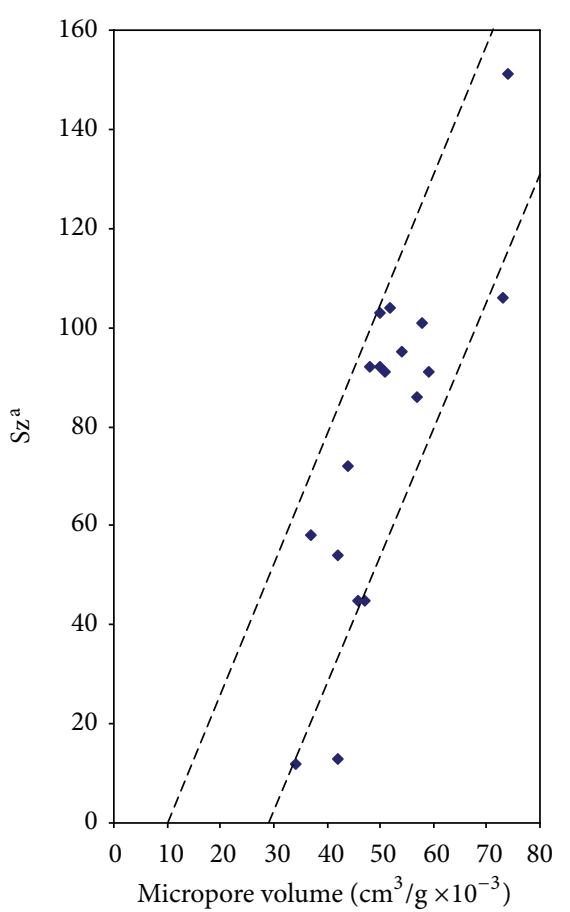

FIGURE 1: Value of spontaneous combustion index $\mathrm{Sz}^{\mathrm{a}}$ of coal as a function of micropore volume.

an easy access of the carbon dioxide molecules to the coal structure. The adsorption of carbon dioxide takes place in the entire coal structure, both on the outer surfaces and inside the microporous structure, as confirmed in many studies [24]. Considering the $\mathrm{CO}_{2}$ adsorption in micropores of hard coals, hydroxyl groups present in the coal structure may be of great importance, as they can electrostatically interact with the $\mathrm{CO}_{2}$ molecule having a double dipole character.

Figure 1 shows the dependence of the values of spontaneous combustion index $\mathrm{Sz}^{\mathrm{a}}$ on micropore volumes, determined from the course of the $\mathrm{CO}_{2}$ adsorption isotherms. Analyzing this relationship, it can be seen that the values of the index rise with the increasing micropore volume. This relationship is not linear but in a band form, with a rather large scatter of data. Similarly, Figure 2 presents the dependence of the values of spontaneous combustion index $\mathrm{Sz}^{\mathrm{a}^{\prime}}$ on micropore volumes. In this case data are also scattered but the values of index are lower. The index $\mathrm{Sz}^{\mathrm{a}^{\prime}}$ is determined in the process of its oxidation in air at lower temperature of $463 \mathrm{~K}$. The data presented in Figures 1 and 2 distinctly show the impact of micropore volume on the values of coal spontaneous combustion indexes $\mathrm{Sz}^{\mathrm{a}}$ and $\mathrm{Sz}^{\mathrm{a}^{\prime}}$ symbols and thereby confirm the clear influence of the inside microporous structure of coals on their susceptibility to spontaneous combustion.

Coals selected for tests are characterized by different values of spontaneous combustion indexes, from the lowest values characteristic of I group of spontaneous combustion up to high values of indexes corresponding to coals demonstrating high tendency to self-ignition $-\mathrm{V}$ group of 


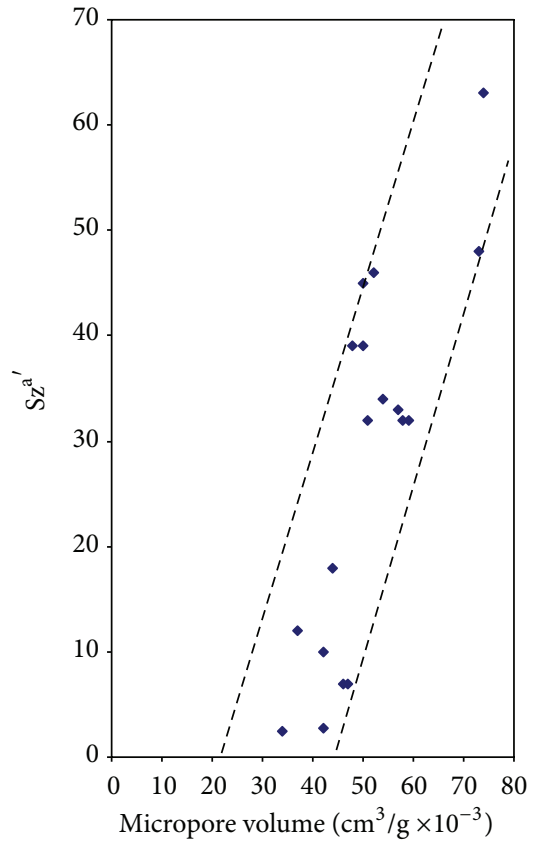

FIGURE 2: Value of spontaneous combustion index $S z^{a^{\prime}}$ of coal as a function of micropore volume.

spontaneous combustion (Table 2). The participation of micropore volume in the oxidation processes applies to all coals, from the highest-rank coals with organized structure whose susceptibility to spontaneous combustion is usually low to those with the lowest percentage of carbon and the highest tendency to spontaneous combustion. Due to a diversity of the micropore volume values obtained from $\mathrm{CO}_{2}$ adsorption, they can be used to determine the degree of spontaneous combustion tendency of coal.

4.2. Relationship between Macropore Surface and a Susceptibility of Hard Coals to Spontaneous Combustion. Larger mesopores and macropores, the so-called transport pores, are responsible for the transport of sorbed gas (oxygen) into the deep inside of the coal structure. At the initial stage, self-heating of coal is determined by the amount of oxygen adsorbed in macropores and mesopores of the given hard coal. Some authors claim that it is macropores, treated as transport arteries for the molecules of penetrating gas, that make a significant contribution to the processes of coal oxidation [5]. According to [25], pores of a size less than $100 \AA$ do not contribute to the reaction of lowtemperature oxidation due to the lack of microdiffusion. For macropore surface area examination the measurements of nitrogen adsorption have been proposed. In many research studies on the adsorption of nitrogen conducted at $77.5 \mathrm{~K}$ on hard coals it has been shown that in those conditions nitrogen is adsorbed only on the inner walls of macropores. At the temperature of liquid nitrogen coal contracts what causes the narrowing of the fine capillaries, preventing the movement of the nitrogen molecules into the inside of further micropores [23]. The influence of the diffusion factor is also

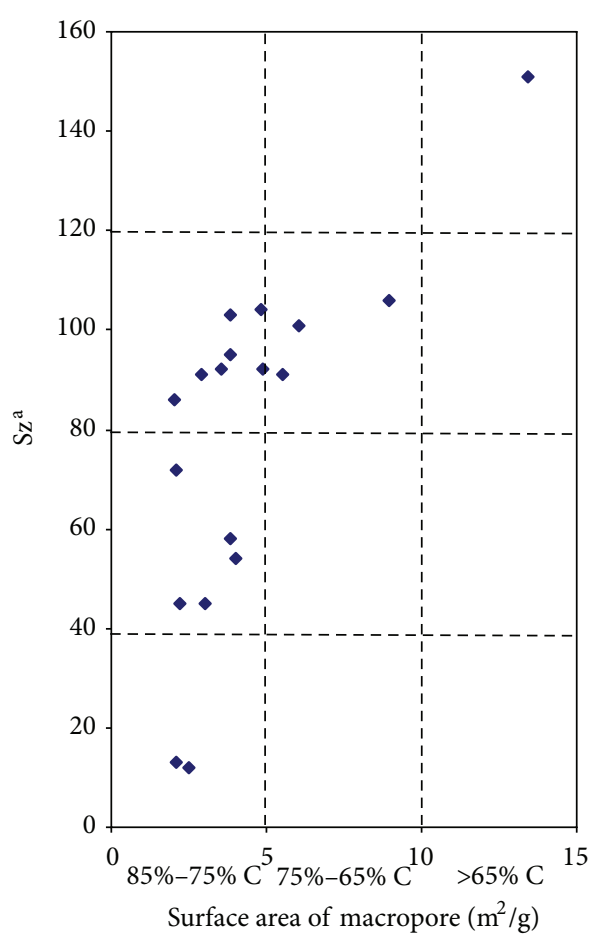

FIgURE 3: Value of spontaneous combustion index $\mathrm{Sz}^{\mathrm{a}}$ of coal as a function of macropore surface area.

being taken into account. Low temperature causes a reduction in the kinetic energy of the nitrogen molecules penetrating the capillaries which stops them in narrow capillaries of the porous coal structure. In the theory of diffusion processes it is assumed that gases penetrating into micropores are first collected in macropores and then transmitted through the mesopore system into micro- and submicropores [26]. In the case of low volume of macropores not all micropores receive enough oxygen which results in slowing down the process of coal oxidation. In literature the issue concerning coal susceptibility to spontaneous combustion resulting from the value of the macropores surface area has been rarely discussed. The obtained tests results were used to plot graphs shown in Figures 3 and 4.

Figure 3 shows the dependence of the values of $\mathrm{Sz}^{\mathrm{a}}$ index on the macropore surface area. The plotted curve features a band character. After dividing the graph into several rectangular areas a few important remarks can be made. The values of $\mathrm{Sz}^{\mathrm{a}}$ index falling within a range of macropore surface area values of $1-5 \mathrm{~m}^{2} / \mathrm{g}$ include most of the tested coals and show a gradual increase in the value of this index with a little change of the surface area value. A significant share of these coals demonstrates a similar macropore surface area in the order of $2-3 \mathrm{~m}^{2} / \mathrm{g}$, although the values of spontaneous combustion indexes of those coals are varied and comprise IIII groups of spontaneous combustion. Coals falling into this range are coals of higher rank with the carbon content of 75$85 \%$. Probably the low value of macropore surface area can hinder the access of adsorbed gases to the inside microporous structure of coals, which can slow down the process of oxidation. It is slightly different in the case of lower-rank 
coals with the loose structure, whose carbon content is less than $75 \% \mathrm{C}$. For those coals the values of macropore surface area differ more. In this case an increase in the spontaneous combustion index is concurrent with a clear increase in the macropore surface area.

In Figure 4 an analogous graph concerning the relationship between the values of $\mathrm{Sz}^{\mathrm{a}^{\prime}}$ index and macropore surface area is shown. The values of the index discussed in the range of the low values of macropore surface area (1$5 \mathrm{~m}^{2} / \mathrm{g}$ ) are distinctly different, as in the case of $\mathrm{Sz}^{\mathrm{a}}$ index. With an increase in the surface area of macropores of more than $5 \mathrm{~m}^{2} / \mathrm{g}$ the coals already demonstrate quite a high tendency to spontaneous combustion which, undoubtedly, is also associated with a variety of energetic centers on their surface and with a significant increase in the number of reactive groups containing oxygen.

The low values of macropore surface area are the result of physical adsorption characterized by weak dispersion force interactions occurring between the nitrogen molecules and the coal substance. The values of macropore surface area can also be used to evaluate the tendency of coal to spontaneous combustion, although the index expressed by macropore surface area seems to be better only for coals having lower carbon content (below $75 \% \mathrm{C}$ ). For coals of the higher degree of metamorphism, the values of specific surface area are similar, although the index values of those coals are very much different.

\section{Conclusions}

Summing up the presented tests results it can be concluded that there certainly is a relationship between pore volume of hard coals and their tendency to spontaneous combustion.

(1) Micropore volumes of coals determined on the basis of the carbon dioxide adsorption isotherms increase with the values of spontaneous combustion indexes $\mathrm{Sz}^{\mathrm{a}}$ and $\mathrm{Sz}^{\mathrm{z}^{\prime}}$ of coal according to the standard PN93/G-04558. Coals with higher values of micropore volume are more prone to spontaneous combustion.

(2) Macropore surface areas determined on the basis of the nitrogen adsorption isotherms also correlate with the values of spontaneous combustion indexes. Highrank coals demonstrate a small change in the surface area of macropores in relation to changes in the values of spontaneous combustion indexes. In the case of coals of lower rank there is a clear rise in spontaneous combustion indexes with the increasing macropore surface area.

(3) Pore volume determined from the adsorption of carbon dioxide seems to be a better parameter that can be used to assess the susceptibility of coal to spontaneous combustion. The molecules of carbon dioxide are well adsorbed in the pore structure of coal; the temperature during measurements is similar to the actual conditions in situ and at the same time there is a greater diversity of micropore volumes compared to the macropore surface area.

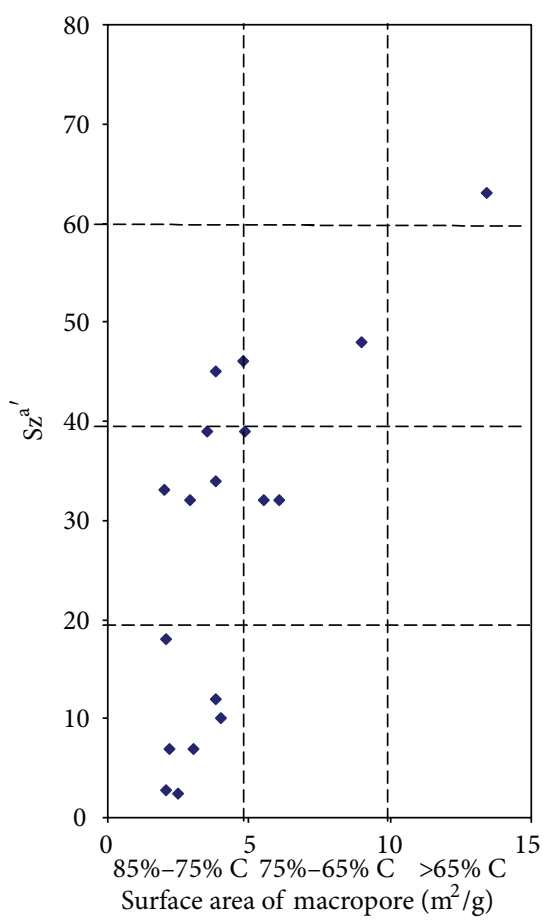

FIGURE 4: Value of spontaneous combustion index $\mathrm{Sz}^{\mathrm{a}^{\prime}}$ of coal as a function of macropore surface area.

\section{Conflict of Interests}

The author declares that there is no conflict of interests regarding the publication of this paper.

\section{References}

[1] G. Ceglarska-Stefańska, A. Czapliński, P. Fudalej, and S. Hołda, "Polimeryczny model węgla kamiennego w świetle wysokociśnieniowych badań sorpcyjnych i dylatometrycznych," Archives of Mining Sciences, vol. 20, pp. 299-305, 1975.

[2] C. R. Clarkson and R. M. Bustin, "Effect of pore structure and gas pressure upon the transport properties of coal: a laboratory and modeling study. 1 . Isotherms and pore volume distributions," Fuel, vol. 78, no. 11, pp. 1333-1344, 1999.

[3] A. Czapliński, Węgiel Kamienny, Wydawnictwa AGH, Kraków, Poland, 1994.

[4] Q. I. Xuyao, "Characteristics of oxygen consumption of coal at programmed temperatures," Mining Sciences and Technology, vol. 20, pp. 0372-0377, 2010.

[5] Y. S. Nugroho, A. C. McIntosh, and B. M. Gibbs, "Low-temperature oxidation of single and blended coals," Fuel, vol. 79, no. 15, pp. 1951-1961, 2000.

[6] X. Wang, R. He, and Y. Chen, "Evolution of porous fractal properties during coal devolatilization," Fuel, vol. 87, no. 6, pp. 878-884, 2008.

[7] H. Wang, B. Z. Dlugogorski, and E. M. Kennedy, "Coal oxidation at low temperatures: oxygen consumption, oxidation products, reaction mechanism and kinetic modelling," Progress in Energy and Combustion Science, vol. 29, no. 6, pp. 487-513, 2003. 
[8] O. P. Mahajan, " $\mathrm{CO}_{2}$ surface area of coals: the 25-year paradox," Carbon, vol. 29, no. 6, pp. 735-742, 1991.

[9] J. H. Levy, S. J. Day, and J. S. Killingley, "Methane capacities of Bowen Basin coals related to coal properties," Fuel, vol. 76, no. 9, pp. 813-819, 1997.

[10] J. Cygankiewicz, A. Dudzińska, and M. Żyła, "Sorption and desorption of carbon monoxide in several samples of polish hard coal," Archives of Mining Sciences, vol. 52, no. 4, pp. 573$585,2007$.

[11] J. Cygankiewicz, A. Dudzińska, and M. Żyła, "The relation between the size of bituminous coal particles and the sorption of carbon monoxide," Gospodarka Surowcami Mineralnymi/ Mineral Resources Management, vol. 25, no. 1, pp. 85-100, 2009.

[12] M. Żyła, A. Dudzińska, and J. Cygankiewicz, "The relation between ambient temperature and sorption of carbon monoxide on bituminous coals," Gospodarka Surowcami Mineralnymi/ Mineral Resources Management, vol. 25, no. 4, pp. 33-49, 2009.

[13] J. Cygankiewicz, A. Dudzińska, and M. Żyła, "Examination of sorption and desorption of hydrogen on several samples of polish hard coals," Adsorption, vol. 18, no. 3-4, pp. 189-198, 2012.

[14] M. Żyła, A. Dudzińska, and J. Cygankiewicz, "The influence of disintegration of hard coal varieties of different metamorphism grade on the amount of absorbed ethane," Archives of Mining Sciences, vol. 58, no. 2, pp. 449-463, 2013.

[15] A. Dudzińska, M. Żyła, and J. Cygankiewicz, "Influence of the metamorphism grade and porosity of hard coal on sorption and desorption of propane," Archives of Mining Sciences, vol. 58, no. 3, pp. 859-871, 2013.

[16] A. G. Kim, "Laboratory studies on spontaneous heating of coal-a summary of information in the literature," U.S. Bureau of Mines, no. 8756, 1977.

[17] J. M. Kuchta, V. R. Rowe, and D. S. Burgess, "Spontaneous combustion susceptibility of U.S. coals," Bureau of Mines Report of Investigation, vol. 37, no. 8474, 1980.

[18] T. X. Ren and M. J. Richards, "Computerised system for the study of the spontaneous combustion of coal," Mining Engineer London, vol. 154, no. 398, pp. 121-127, 1994.

[19] G. Y. Qian, "Research on the use of spectrum technique for determining the liability of coal to spontaneous combustion fushun coal reserch institute of technology," P.R. China, 1987 (Chinese).

[20] K. K. Feng, R. N. Chakravorty, and T. S. Cochrane, "Spontaneous combustion-a coal mining hazard," C/M Bulletin, vol. 66, no. 738, pp. 75-84, 1973.

[21] P. Chowdhury, C. Bikkina, and S. Gumma, "Gas adsorption properties of the chromium-based metal organic framework MIL-101," Journal of Physical Chemistry C, vol. 113, no. 16, pp. 6616-6621, 2009.

[22] K. Zarębska, P. Baran, J. Cygankiewicz, and A. Dudzińska, "Sorption of carbon dioxide on polish coals in low and elevated pressure," Fresenius. Environmental Biulletin, vol. 21, pp. 40034008, 2012.

[23] J. Cygankiewicz, A. Dudzińska, and M. Żyła, “The effect of particle size of comminuted bituminous coal on low-temperature sorption of nitrogen and room-temperature sorption of carbon dioxide," Przemysl Chemiczny, vol. 85, no. 11, pp. 1505-1509, 2006.

[24] B. M. Krooss, F. Van Bergen, Y. Gensterblum, N. Siemons, H. J. M. Pagnier, and P. David, "High-pressure methane and carbon dioxide adsorption on dry and moisture-equilibrated Pennsylvanian coals," International Journal of Coal Geology, vol. 51, no. 2, pp. 69-92, 2002.
[25] R. Kaji, Y. Hishinuma, and Y. Nakamura, "Low temperature oxidation of coals. Effects of pore structure and coal composition," Fuel, vol. 64, no. 3, pp. 297-302, 1985.

[26] D. Prinz, W. Pyckhout-Hintzen, and R. Littke, "Development of the meso- and macroporous structure of coals with rank as analysed with small angle neutron scattering and adsorption experiments," Fuel, vol. 83, no. 4-5, pp. 547-556, 2004. 

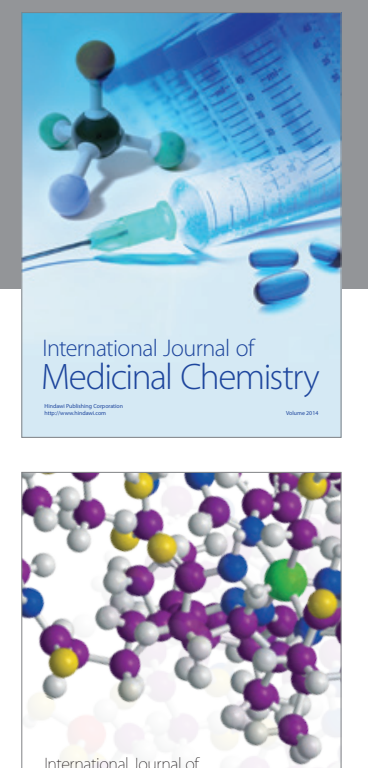

\section{Carbohydrate} Chemistry

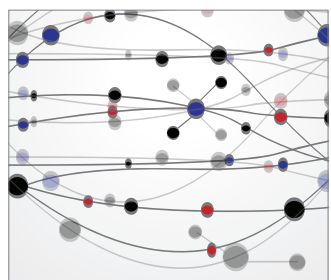

The Scientific World Journal
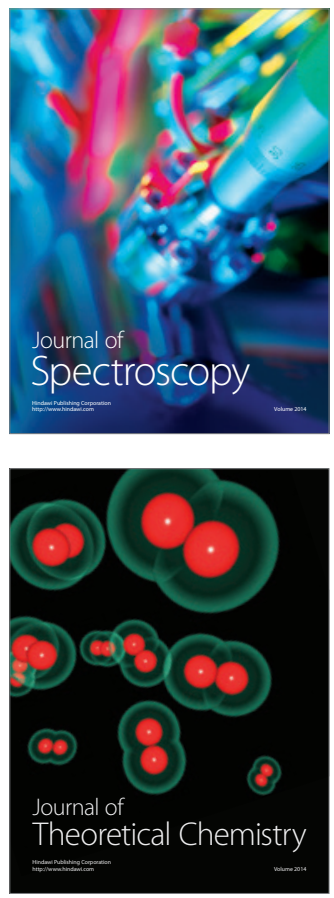
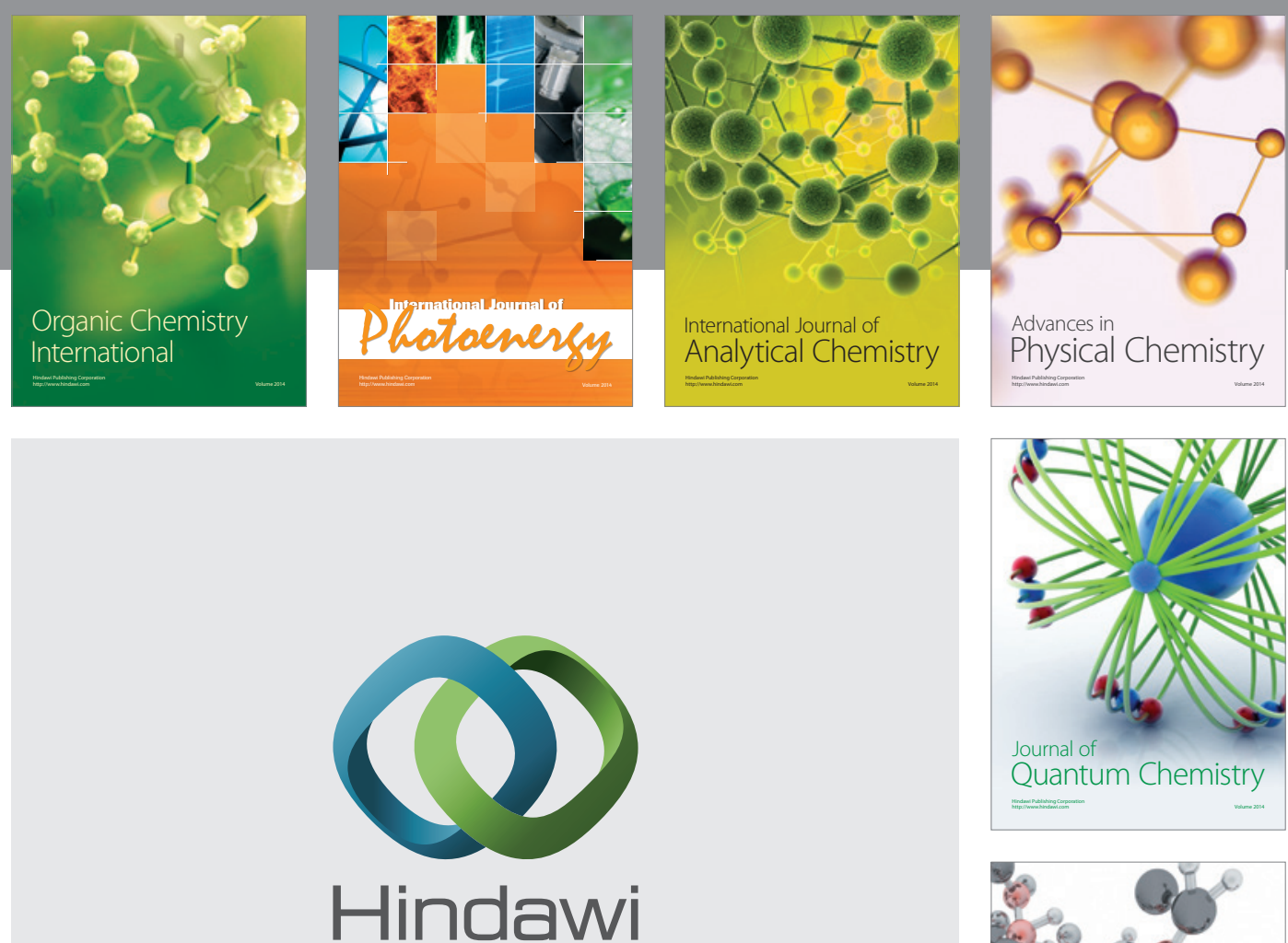

Submit your manuscripts at

http://www.hindawi.com

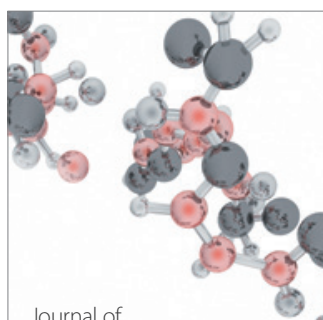

Analytical Methods

in Chemistry

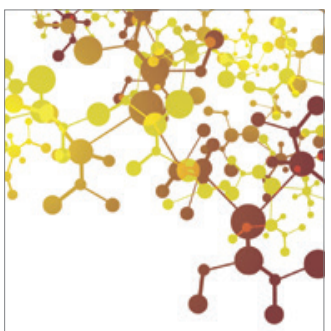

Journal of

Applied Chemistry

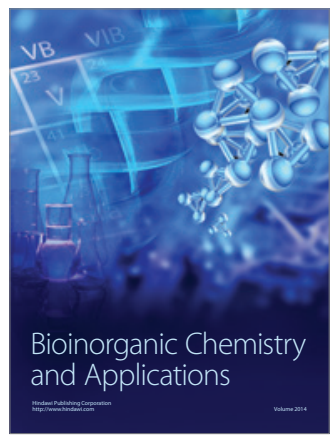

Inorganic Chemistry
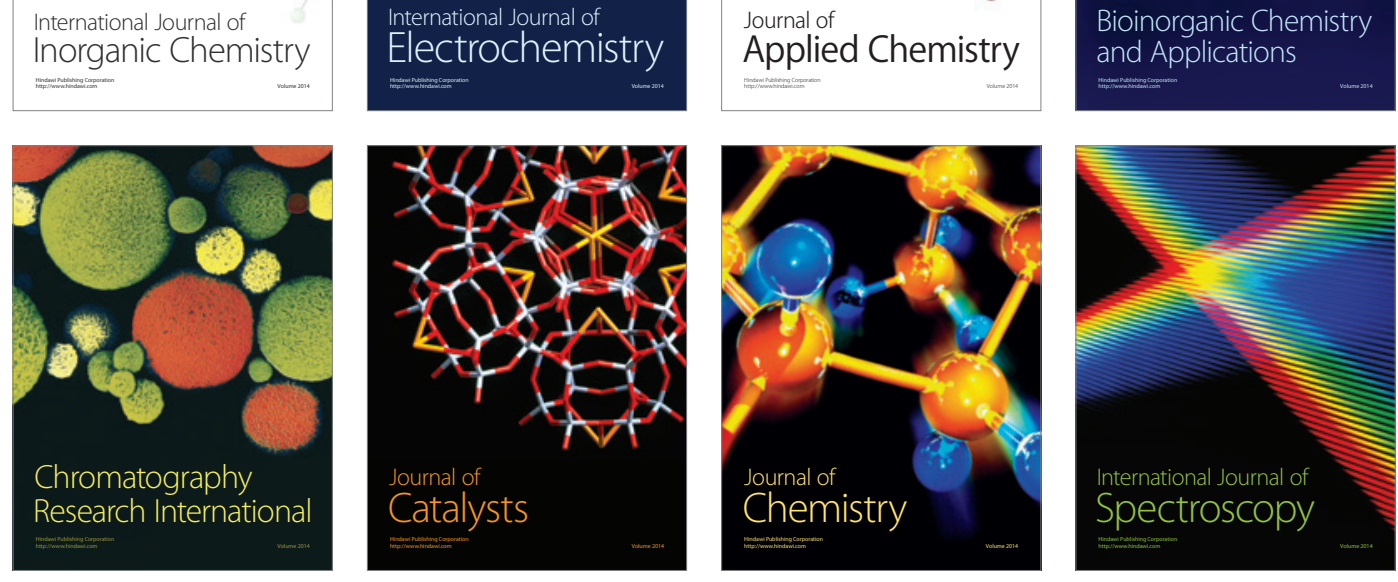